\title{
METODE SMALL AREA ESTIMATION HIERARCHICAL BAYES DALAM PENDUGAAN PERSENTASE KASUS PENYAKIT KUSTA BASAH DI PROVINSI JAWA TIMUR TAHUN 2018
}

\author{
NADIA HUSNA, HAZMIRA YOZZA, DODI DEVIANTO \\ Program Studi S1 Matematika, \\ Fakultas Matematika dan Ilmu Pengetahuan Alam, Universitas Andalas, \\ Kampus UNAND Limau Manis Padang, Indonesia. \\ email : nadia98husna@gmail.com
}

Diterima 16 Juni 2020 Direvisi 22 Juni 2020 Dipublikasikan 13 Juli 2020

\begin{abstract}
Abstrak. Kusta adalah penyakit infeksi kronis yang disebabkan oleh bakteri yang disebut Mycrobacterium leprae yang menyerang saraf tepi, kulit dan jaringan tubuh lainnya. Kusta memiliki dua tipe yaitu kusta kering dan kusta basah. Penyakit kusta basah sangat mudah menular sehingga kasus kusta basah lebih banyak terjadi. Pada penelitian ini dilakukan pendugaan persentase kasus penyakit kusta basah di Provinsi Jawa Timur tahun 2018. Pendugaan dilakukan dengan penduga langsung dan dengan menggunakan metode Small Area Estimation Hierarchical Bayes. Hasil penelitian ini menunjukkan bahwa pendugaan persentase kusta basah dengan menggunakan metode Small Area Estimation Hierarchical Bayes diperoleh pada semua kabupaten/kota yang nilai dugaan persentase kusta basahnya diatas $90 \%$ dengan rata-rata pendugaan 0, 9550 dan cenderung lebih baik karena dilihat dari nilai standard error-nya yang lebih kecil dibandingkan dengan penduga langsung.
\end{abstract}

Kata Kunci: Kusta, Small Are Estimation, Hierarchical Bayes

\section{Pendahuluan}

Penyakit kusta merupakan penyakit menular yang disebabkan oleh infeksi $M y$ crobacterium leprae yang menyerang berbagai bagian tubuh di antaranya saraf dan kulit. Penyakit kusta memiliki dua tipe penderita yaitu penderita kusta kering dan penderita kusta basah. Kusta basah sangat mudah menular sehingga memiliki kasus yang lebih banyak. Provinsi Jawa Timur memiliki angka beban kusta tertinggi di Indonesia, berbagai program telah dilakukan namun masih banyak masyarakat yang menderita kusta. Agar program-program yang dilakukan tepat maka perlu diduga berapa persentase yang sesungguhnya menderita kusta basah atau kusta kering.

Pendugaan persentase kusta basah dilakukan dengan penduga langsung, karena ketersedian data di kabupaten/kota masih belum mencukupi untuk menduga

*penulis korespondensi 
persentase kusta basah sehingga dengan ukuran sampel yang kecil akan menghasilkan ragam yang besar dan akan mempengaruhi keakuratan data tersebut. Agar tingkat akurasi lebih baik maka digunakan pendugaan tidak langsung menggunakan metode Small Area Estimation Hierarchical Bayes dengan meminjam informasi dari kabupaten/kota dan peubah penyerta lainnya. Peubah penyerta disini adalah faktor-faktor yang terkait dengan kusta, dengan mengetahui faktor-faktor tersebut pemerintah memilki gambaran langkah apa saja yang harus dilakukan dalam menekan angka kasus penyakit kusta di Provinsi Jawa Timur.

\section{Landasan Teori}

\subsection{Penduga Maximum Likelihood}

Metode maximum likelihood merupakan metode yang sangat berguna untuk mendapatkan penduga langsung bagi parameter. Metode penduga maximum likelihood adalah metode pendugaan parameter yang dilakukan dengan memaksimumkan fungsi likelihood yang didefinisikan sebagai berikut.

Definisi 2.1. [1] Fungsi kepekatan peluang peubah acak $X_{1}, X_{2}, \cdots, X_{n}$ yang dihitung pada $x_{1}, x_{2}, \cdots, x_{n}$ ditulis dalam bentuk $f\left(x_{1}, x_{2}, \cdots, x_{n} \mid \theta\right)$. Untuk $x_{1}, x_{2}, \cdots, x_{n}$ tetap, fungsi likelihood adalah fungsi dari parameter bernilai $\theta$ yang dinotasikan dengan $L(\theta)$. Jika $X_{1}, X_{2}, \cdots, X_{n}$ merupakan sampel acak dari $f(x \mid \theta)$ maka

$$
\begin{aligned}
L(\theta) & =f\left(x_{1} ; \theta\right) f\left(x_{2} ; \theta\right) \cdots f\left(x_{n} ; \theta\right), \\
& =\prod_{i=1}^{n} f\left(x_{i} ; \theta\right) .
\end{aligned}
$$

\subsection{Metode Pendugaan Parameter Menggunakan Metode Bayes}

Metode Bayes didasarkan pada distribusi posterior yang diperoleh melalui teorema Bayes dari distribusi prior dan dari data observasi yang digunakan untuk menyusun fungsi likelihood. Misalkan $f(\theta)$ adalah distribusi prior dan $f(\boldsymbol{x} \mid \theta)$ adalah fungsi likelihood dari $\boldsymbol{X}=\left(X_{1}, X_{2}, \cdots, X_{n}\right)$, maka fungsi kepekatan peluang posterior sebagai berikut [4]

$$
f(\theta \mid \boldsymbol{x})=\frac{f(\boldsymbol{x} \mid \theta) f(\theta)}{f(\boldsymbol{x})} .
$$

Fungsi $f(\boldsymbol{x})$ merupakan normalizing constant yang tidak bergantung pada parameter sehingga persamaan (2.1) dapat ditulis menjadi

$$
f(\theta \mid \boldsymbol{x}) \propto f(\boldsymbol{x} \mid \theta) f(\theta) .
$$

\subsection{Small Area Estimation (SAE)}

Small Area Estimation merupakan suatu teknik statistika untuk menduga parameter-parameter subpopulasi berdasarkan sampel yang ukurannya kecil. Small 
Area Estimation terdiri dari dua model dasar yaitu model berbasis level area (basic area level model) dan model berbasis level unit (basic unit level model).

Basic area level, atau dapat disebut model level area, merupakan model yang didasarkan pada ketersediaan data pendukung yang hanya ada untuk area tertentu [5]. Misalkan $\boldsymbol{x}_{\mathrm{i}}=\left(x_{1 i}, x_{2 i}, \cdots, x_{p i}\right)^{T}$ suatu vektor dimana $i$ merupakan banyaknya area ke- $i$. Pada model ini, parameter yang akan diduga $\theta_{i}$ diasumsikan memiliki hubungan dengan $\boldsymbol{x}_{i}$ dan mengikuti model linier

$$
\theta_{i}=\boldsymbol{x}_{i}^{T} \boldsymbol{\beta}+v_{i}, i=1,2, \cdots, m .
$$

dimana $\boldsymbol{\beta}=\left(\beta_{1}, \beta_{2}, \cdots, \beta_{p}\right)^{T}$ adalah vektor koefisien regresi berukuran $p \times 1$ dan $v_{i}$ adalah pengaruh acak yang diasumsikan menyebar $N\left(0, \sigma_{v}^{2}\right)$.

Penduga $\theta_{i}$ dapat diketahui dengan mengasumsikan bahwa model penduga langsung $\widehat{\theta}_{i}$ ada, yaitu

$$
\widehat{\theta_{i}}=\theta_{i}+e_{i}, i=1,2, \cdots, m,
$$

dengan sampling error pada area ke- $i$ yang diasumsikan $e_{i} \sim N\left(0, \psi_{i}\right)$, dengan $\psi_{i}$ diketahui [5]. Berdasarkan persamaan (2.3) maka persamaan (2.4) akan menghasilkan model gabungan sebagai berikut:

$$
\widehat{\theta_{i}}=\boldsymbol{x}_{i}^{T} \boldsymbol{\beta}+v_{i}+e_{i}, i=1,2, \cdots, m .
$$

\subsection{Metode Hierarchical Bayes pada SAE}

Metode Hierarchical Bayes (HB) merupakan metode yang mengasumsikan suatu distribusi prior dari suatu parameter dan teorema Bayes digunakan untuk mendefinisikan distribusi posterior dari parameter tersebut [5].

Dalam pendekatan HB, dinyatakan terlebih dahulu sebaran prior subjektif parameter model $\theta$, kemudian untuk gugus data $y$ diperoleh sebaran posterior $f(\theta \mid y)$ dari parameter $\theta$ yang diamati $f(\theta)$. Secara khusus, inferensi yang didasarkan pada sebaran posterior untuk parameter tersebut diduga melalui rata-rata posterior, dan presisinya diukur melalui ragam posterior [5].

\section{Metode Penelitian}

Data yang digunakan dalam penelitian ini adalah data jumlah kasus kusta di kabupaten/kota Provinsi Jawa Timur tahun 2018. Data pada penelitian ini didapatkan dari Profil Kesehatan Provinsi Jawa Timur tahun 2018.

Peubah respon dalam penelitian ini adalah jumlah kasus kusta basah di 38 kabupaten/kota di Provinsi Jawa Timur tahun 2018. Peubah penyerta terkait dengan penyakit kusta basah yang digunakan dalam penelitian ini adalah persentase rumah sehat $\left(X_{1}\right)$, persentase keluarga berpemilikan sanitasi layak $\left(X_{2}\right)$, kepadatan penduduk $\left(X_{3}\right)$, persentase rumah tangga beperilaku hidup bersih dan sehat $\left(X_{4}\right)$, persentase rumah tangga yang memiliki sarana air bersih $\left(X_{5}\right)$.

Tahap-tahap yang dilakukan adalah :

(1) Mendeskripsikan peubah penyerta (X) dan peubah respon (Y).

(2) Melakukan pendugaan langsung dan menghitung standard errornya. 
(3) Melakukan pendugaan tidak langsung menggunakan metode Small Area Estimation Hierarchical Bayes dan menghitung standard errornya.

(4) Menghitung perbandingan hasil pendugaan langsung dengan pendugaan tidak langsung begitu juga nilai standard errornya.

\section{Pembahasan}

\subsection{Pendugaan Langsung Menggunakan Maximum Likelihood}

Penduga maximum likelihood diperoleh dengan menentukan terlebih dahulu fungsi likelihood. Penduga diperoleh dengan memaksimumkan fungsi tersebut, hal ini sama dengan memaksimumkan log likelihoodnya. Caranya dengan menurunkan fungsi tersebut terhadap parameter yang akan diduga lalu samakan dengan nol.

Misalkan $U_{i}$ contoh acak Bernoulli bernilai 1 dan 0 sehingga fungsi kepekatan peluangnya menjadi

$$
f\left(u_{i} \mid p\right)=p^{u_{i}}(1-p)^{1-u_{i}}, u_{i}=0,1 .
$$

Selanjutnya fungsi likelihood dinyatakan sebagai

$$
\begin{aligned}
L\left(p \mid u_{i}\right) & =\prod_{i=1}^{n} f\left(u_{i} \mid p\right) \\
& =p^{\sum_{i=1}^{n} u_{i}}(1-p)^{n-\sum_{i=1}^{n} u_{i}} .
\end{aligned}
$$

Fungsi log likelihood dari distribusi ini adalah

$$
\begin{aligned}
\ln \left(L\left(p \mid u_{i}\right)\right) & =\ln \left(p^{\sum_{i=1}^{n} u_{i}}(1-p)^{n-\sum_{i=1}^{n} u_{i}}\right) \\
& =\ln p \sum_{i=1}^{n} u_{i}+\ln (1-p)\left(n-\sum_{i=1}^{n} u_{i}\right) .
\end{aligned}
$$

Turunan pertama dari fungsi likelihood adalah:

$$
\begin{aligned}
\frac{d}{d p} \ln \left(L\left(p \mid u_{i}\right)\right) & =\frac{d}{d p}\left(\ln p \sum_{i=1}^{n} u_{i}+\ln (1-p)\left(n-\sum_{i=1}^{n} u_{i}\right)\right) \\
& =\frac{\sum_{i=1}^{n} u_{i}}{p}+\frac{n-\sum_{i=1}^{n} u_{i}}{1-p}(-1) .
\end{aligned}
$$

Dengan menyamakannya dengan 0 diperoleh:

$$
\begin{gathered}
\frac{\sum_{i=1}^{n} u_{i}}{p}=\frac{n-\sum_{i=1}^{n} u_{i}}{1-p} \\
p=\frac{\sum_{i=1}^{n} u_{i}}{n} .
\end{gathered}
$$

Jika didefinisikan $Y=\sum_{i=1}^{n} U_{i}$ maka diperoleh penduga maximum likelihood bagi $p$ adalah

$$
\widehat{p}=\frac{Y}{n}
$$


Selanjutnya akan ditentukan nilai standard error dari $\widehat{p}$ dapat dinyatakan sebagai berikut.

$$
\text { Standar } \operatorname{Error}(\widehat{p})=\sqrt{\operatorname{Var}(\widehat{p})} \text {. }
$$

Dengan menggunakan penduga pada persamaan (3.1) diperoleh ragam penduga menjadi

$$
\begin{aligned}
\operatorname{Var}(\widehat{p}) & =\operatorname{Var}\left(\frac{Y}{n}\right) \\
& =\operatorname{Var}\left(\frac{\sum_{i=1}^{n} U_{i}}{n}\right) \\
& =\frac{p(1-p)}{n} .
\end{aligned}
$$

Berdasarkan Persamaan (3.2) diperoleh nilai standart error dari $\widehat{p}$ menjadi

$$
\text { Standar } \operatorname{Error}(\widehat{p})=\sqrt{\frac{p(1-p)}{n}} \text {. }
$$

Hasil penduga langsung dan nilai standar errornya akan disajikan pada Tabel 1 berikut.

Tabel 1. Hasil Pendugaan Langsung Persentase Kasus Penyakit Kusta Basah di Provinsi Jawa Timur Tahun 2018

\begin{tabular}{|l|c|c|}
\hline Kab/Kota & $\widehat{p}_{i}$ & $\mathrm{SE}$ \\
\hline Pacitan & 1,0000 & 0,0000 \\
\hline Ponorogo & 0,9714 & 0,0048 \\
\hline Trenggalek & 1,0000 & 0,0000 \\
\hline Tulunagung & 0,9310 & 0,0088 \\
\hline Blitar & 1,0000 & 0,0000 \\
\hline Kediri & 0,9434 & 0,0044 \\
\hline Malang & 0,9286 & 0,0046 \\
\hline Lumajang & 0,8895 & 0,0017 \\
\hline Jember & 0,9671 & 0,0007 \\
\hline Banyuwang & 0,9459 & 0,0061 \\
\hline Bondowoso & 0,9592 & 0,0040 \\
\hline Situbondo & 0,9355 & 0,0026 \\
\hline Probolinggo & 0,9011 & 0,0016 \\
\hline Pasuruan & 0,9543 & 0,0012 \\
\hline Sidoarjo & 0,9474 & 0,0040 \\
\hline Mojokerto & 0,9783 & 0,0032 \\
\hline Jombang & 0,9474 & 0,0030 \\
\hline Nganjuk & 0,9773 & 0,0034 \\
\hline Madiun & 1,0000 & 0,0000 \\
\hline
\end{tabular}

\begin{tabular}{|l|c|c|}
\hline Kab/Kota & $\widehat{p_{i}}$ & $\mathrm{SE}$ \\
\hline Magetan & 0,9630 & 0,0070 \\
\hline Ngawi & 0,9362 & 0,0052 \\
\hline Bojonegoro & 0,9682 & 0,0028 \\
\hline Tuban & 0,9133 & 0,0016 \\
\hline Lamongan & 0,9437 & 0,0032 \\
\hline Gresik & 0,9468 & 0,0024 \\
\hline Bangkalan & 0,9828 & 0,0006 \\
\hline Sampang & 0,9496 & 0,0005 \\
\hline Pamekasan & 0,9810 & 0,0004 \\
\hline Sumenep & 0,8916 & 0,0008 \\
\hline Kediri & 1,0000 & 0,0000 \\
\hline Blitar & 1,0000 & 0,0000 \\
\hline Malang & 1,0000 & 0,0000 \\
\hline Probolinggo & 0,9091 & 0,0131 \\
\hline Pasuruan & 1,0000 & 0,0000 \\
\hline Mojokerto & 1,0000 & 0,0000 \\
\hline Madiun & 1,0000 & 0,0000 \\
\hline Surabaya & 1,0000 & 0,0000 \\
\hline Batu & 0,5000 & 0,2500 \\
\hline
\end{tabular}

Berdasarkan Tabel 1 dapat dilihat bahwa dengan menggunakan penduga langsung pada beberapa kabupaten/kota diduga $90 \%$ penderita kusta di kabupaten/kota 
Provinsi Jawa Timur itu mengalami kusta basah. Dengan kecilnya ukuran sampel di beberapa kabupaten/kota tersebut, diperkirakan pendugaan yang dilakukan tidak akurat, sehingga pendugaan akan dilakukan secara tidak langsung agar pendugaannya lebih akurat

\subsection{Pendugaan Tidak Langsung Kasus Penyakit Kusta Basah Di Provini Jawa Timur}

Pada penelitian ini model HB yang digunakan adalah model Logitnormal dengan peubah penyerta berbasis area [5]. Pada model ini,

(i) sampling model yang digunakan adalah

$$
y_{i} \mid p_{i} \sim \operatorname{Binomial}\left(n_{i}, p_{i}\right) .
$$

(ii) linking model yang digunakan adalah

$$
\xi_{i}=\operatorname{logit}\left(p_{i}\right)=\boldsymbol{x}_{i}^{T} \boldsymbol{\beta}+v_{i}, v_{i} \sim\left(0, \sigma_{v}^{2}\right) .
$$

(iii) parameter $\boldsymbol{\beta}$ dan $\sigma_{v}^{2}$ diasumsikan saling bebas dengan

$$
f(\boldsymbol{\beta}) \propto 1 ; \sigma_{v}^{-2} \sim G A M(a, b) ; a \geq 0, b>0 .
$$

Berikut fungsi likelihood untuk model Small Area Estimation dengan fungsi kepekatan peluang sesuai Persamaan (4.3) yaitu

$$
f(\mathbf{y} \mid \boldsymbol{\beta})=\prod_{i=1}^{m}\left(\begin{array}{l}
n_{i} \\
y_{i}
\end{array}\right) p_{i}^{y_{i}}\left(1-p_{i}\right)^{n_{i}-y_{i}} .
$$

Selanjutnya $f(v)$ merupakan distribusi pengaruh acak yang berdistribusi normal $\xi_{i} \sim N\left(\boldsymbol{x}_{i}^{T} \boldsymbol{\beta}, \sigma_{v}^{2}\right)$ sehingga fungsi kepekatan peluangnya menjadi

$$
f(v) \propto \tau_{v}^{m / 2} \exp \left(-\frac{\tau_{v}}{2} \sum_{i=1}^{m}\left(\xi_{i}-\sum_{j=1}^{k} x_{i j} \beta\right)^{2}\right)
$$

Karena $f(\mathbf{y})$ merupakan normalizing constant maka dihasilkan distribusi posterior gabungan akhir dari pendugaan persentase kasus penyakit kusta basah di setiap kabupaten/kota Provinsi Jawa Timur dapat ditulis menjadi

$$
\begin{aligned}
f\left(p_{1}, \cdots, p_{m}, \boldsymbol{\beta}, \tau_{v} \mid \mathbf{y}\right) & \propto\left(\tau_{v}\right)^{b_{\left(\tau_{v}\right)}-1} \exp \left(\frac{-\tau_{v}}{a_{\tau_{v}}}\right) \times \prod_{i=1}^{m}\left(\begin{array}{c}
n_{i} \\
y_{i}
\end{array}\right) p_{i}^{y_{i}}\left(1-p_{i}\right)^{1-y_{i}} \\
& \times \tau_{v}^{m / 2} \exp \left(-\frac{\tau_{v}}{2} \sum_{i=1}^{m}\left(\xi_{i}-\sum_{j=1}^{k} x_{i j} \beta\right)^{2}\right) \times f\left(p_{i}, \boldsymbol{\beta}, \tau_{v}\right)
\end{aligned}
$$

Distribusi posterior marginal dari yang didapat untuk setiap parameter sangat kompleks sehingga digunakan metode Markov Chan Monte Carlo (MCMC), dengan algoritma Gibss Sampling dilakukan sebanyak 10.000 iterasi, dengan nilai $a$ dan $b$ pada Gamma masing-masing 0,0001 sebagaimana disajikan pada Tabel 2 berikut.

Berdasarkan hasil Tabel 2 diperoleh model untuk menduga persentase kusta basah di kabupaten/kota Provinsi Jawa Timur sebagai berikut. 
Tabel 2. Nilai Parameter Metode SAE HB dalam Pendugaan Persentase Kasus Penyakit Kusta Basah di Provinsi Jawa Timur

\begin{tabular}{|c|c|c|c|c|}
\hline Parameter & Mean & $2.5 \%$ & $97.5 \%$ & MC error \\
\hline$\beta_{0}$ & 1,6550 & $-0,13360$ & 3,6150 & 0,01190 \\
\hline$\beta_{1}$ & 0,0005 & $-0,01622$ & 0,0168 & 0,00009 \\
\hline$\beta_{2}$ & 0,0056 & $-0,02063$ & 0,0311 & 0,00020 \\
\hline$\beta_{3}$ & 0,0003 & 0,00005 & 0,0007 & 0,00000 \\
\hline$\beta_{4}$ & $-0,0025$ & $-0,01887$ & 0,0143 & 0,00008 \\
\hline$\beta_{5}$ & 0,0091 & $-0,00808$ & 0,0267 & 0,00009 \\
\hline$\sigma_{v}^{2}$ & 0,4597 & 0,20750 & 0,7864 & 0,00162 \\
\hline
\end{tabular}

$\operatorname{logit}\left(p_{i}\right)=1,655+0,0005 x_{1 i}+0,0056 x_{2 i}+0,0003 x_{3 i}-0,0025 x_{4 i}+0,0091 x_{5 i}+v_{i}$

Dengan model tersebut maka dapat dilakukan pendugaan persentase kusta basah tiap kabupaten/kota di Provinsi Jawa Timur pada tahun 2018. Untuk menguji kekonvergenannya lebih lanjut maka dapat dilihat pada diagnostic plot yang terdiri dari trace plot, autocorrelation plot, dan density plot.

\subsection{Perbandingan Pendugaan Langsung dan Pendugaan Tidak langsung Kasus Penyakit Kusta Basah}

Perbandingan nilai pendugaan langsung dan pendugaan tidak langsumg disajikan pada Tabel 3 berikut.

Tabel 3. Perbandingan Penduga Langsung dan Pendugaan Tidak Langsung Persentase Kasus Kusta Basah

\begin{tabular}{|l|c|c|}
\hline Kab/Kota & $\widehat{p}_{i}$ & $\widehat{p}_{i}{ }^{H B}$ \\
\hline Pacitan & 1,0000 & 0,9531 \\
\hline Ponorogo & 0,9714 & 0,9567 \\
\hline Trenggalek & 1,0000 & 0,9548 \\
\hline Tulunagung & 0,9310 & 0,9420 \\
\hline Blitar & 1,0000 & 0,9526 \\
\hline Kediri & 0,9434 & 0,9508 \\
\hline Malang & 0,9286 & 0,9331 \\
\hline Lumajang & 0,8895 & 0,9063 \\
\hline Jember & 0,9671 & 0,9592 \\
\hline Banyuwang & 0,9459 & 0,9417 \\
\hline Bondowoso & 0,9592 & 0,9525 \\
\hline Situbondo & 0,9355 & 0,9167 \\
\hline Probolinggo & 0,9011 & 0,9116 \\
\hline Pasuruan & 0,9543 & 0,9550 \\
\hline
\end{tabular}

\begin{tabular}{|l|c|c|}
\hline Kab/Kota & $\widehat{p}_{i}$ & $\widehat{p}_{i}{ }^{H B}$ \\
\hline Magetan & 0,9630 & 0,9551 \\
\hline Ngawi & 0,9362 & 0,9422 \\
\hline Bojonegoro & 0,9682 & 0,9603 \\
\hline Tuban & 0,9133 & 0,9235 \\
\hline Lamongan & 0,9437 & 0,9493 \\
\hline Gresik & 0,9468 & 0,9499 \\
\hline Bangkalan & 0,9828 & 0,9703 \\
\hline Sampang & 0,9496 & 0,9485 \\
\hline Pamekasan & 0,9810 & 0,9749 \\
\hline Sumenep & 0,8916 & 0,9003 \\
\hline Kediri & 1,0000 & 0,9853 \\
\hline Blitar & 1,0000 & 0,9766 \\
\hline Malang & 1,0000 & 0,9892 \\
\hline Probolinggo & 0,9091 & 0,9774 \\
\hline
\end{tabular}




\begin{tabular}{|l|l|l|}
\hline Sidoarjo & 0,9474 & 0,9696 \\
\hline Mojokerto & 0,9783 & 0,9530 \\
\hline Jombang & 0,9474 & 0,9548 \\
\hline Nganjuk & 0,9773 & 0,9619 \\
\hline Madiun & 1,0000 & 0,9509 \\
\hline
\end{tabular}

\begin{tabular}{|l|l|l|}
\hline Pasuruan & 1,0000 & 0,9845 \\
\hline Mojokerto & 1,0000 & 0,9823 \\
\hline Madiun & 1,0000 & 0,9869 \\
\hline Surabaya & 1,0000 & 0,9936 \\
\hline Batu & 0,5000 & 0,9358 \\
\hline
\end{tabular}

Berdasarkan Tabel 3 dapat dilihat bahwa nilai pendugaan langsung dan nilai pendugaan tidak langsung dengan metode Small Area Estimation Hierarchical Bayes pada persentase kasus penyakit kusta basah di Provinsi Jawa Timur memiliki nilai yang hampir sama. Tapi jika dilihat lebih detail, nilai dari pendugaan persentase kasus penyakit kusta basah menggunakan pendekatan Hierarchhical Bayes umumnya sekitar di atas $90 \%$.

Pada Tabel 4 disajikan nilai statistika deskriptif penduga langsung dan pendugaan tidak langsung menggunakan metode Small Area Estimation Hierarchical Bayes dari persentase kusta basah dan standar error-nya.

Tabel 4. Statistika Deskriptif Penduga Langsung dan Penduga Tidak Langsung Metode SAE HB Pada Persentase Kusta Basah dan Standard Errornya

\begin{tabular}{|l|l|c|c|c|}
\hline \multicolumn{1}{|c|}{ Statistik } & $\left(p_{i}\right)$ & $\left(p_{i}^{H B}\right)$ & $\mathrm{SE}\left(\widehat{p}_{i}\right)$ & $\mathrm{SE}\left(\widehat{p}_{i}{ }^{H B}\right)$ \\
\hline Minimum & 0,5000 & 0,9003 & 0,0000 & 0,0004 \\
\hline Maksimum & 1,0000 & 0,9936 & 0,2500 & 0,0350 \\
\hline Mean & 0,9591 & 0,9540 & 0,0099 & 0,0048 \\
\hline Standar Deviasi & 0,0820 & 0,0229 & 0,0039 & 0,0063 \\
\hline
\end{tabular}

Berdasarkan Tabel 4 dalam pendugaan persentase kasus kusta basah di Provinsi Jawa Timur tahun 2018 dapat dilihat bahwa rata-rata dari nilai duga pendugaan HB meghasilkan nilai yang rendah dari rata-rata nilai duga pendugaan secara langsung. Begitu juga pada rata-rata standar error yang dihasilkan dari pendugaan tidak langsung lebih rendah dari rata-rata standar error penduga langsung. Hal ini berati pendugaan tidak langsung dengan metode Small Area Estimation Hierarchical Bayes cenderung lebih baik daripada pendugaan langsung.

\section{Kesimpulan}

Pada pendugaan persentase kusta basah di Provinsi Jawa Timur dengan menggunakan metode Small Area Estimation Hierarchical Bayes diperoleh pada semua kabupaten/kota yang nilai dugaan persentase kusta basahnya diatas $90 \%$ dengan rata-rata pendugaan 0,9550 . Dugaan ini diperoleh menggunakan model logitnormal dengan peubah respon yang menyebar binomial dengan fungsi likelihood yaitu

$$
f(\mathbf{y} \mid \boldsymbol{\beta})=\prod_{i=1}^{m} p_{i}^{y_{i}}\left(1-p_{i}\right)^{1-y_{i}}
$$

dan dengan mengasumsikan bahwa sebaran prior yang flat bagi $\beta$ yang saling bebas dengan $\sigma_{v}^{2}$ menyebar $\operatorname{GAM}(a, b)$ sehingga diperoleh distribusi prior gabungan 
menjadi

$$
f\left(\beta, \tau_{v}\right) \propto\left(\tau_{v}\right)^{b_{\left(\tau_{v}\right)}-1} \exp \left(\frac{-\tau_{v}}{a_{\tau_{v}}}\right) .
$$

Distribusi posterior gabungan akhir dari pendugaan persentase kasus penyakit kusta basah di setiap kabupaten/kota Provinsi Jawa Timur menjadi:

$$
\begin{aligned}
f\left(p_{1}, \cdots, p_{m}, \boldsymbol{\beta}, \tau_{v} \mid \mathbf{y}\right) & \propto\left(\tau_{v}\right)^{b_{\left(\tau_{v}\right)}-1} \exp \left(\frac{-\tau_{v}}{a_{\tau_{v}}}\right) \times \prod_{i=1}^{m}\left(\begin{array}{c}
n_{i} \\
y_{i}
\end{array}\right) p_{i}^{y_{i}}\left(1-p_{i}\right)^{1-y_{i}} \\
& \times \tau_{v}^{m / 2} \exp \left(-\frac{\tau_{v}}{2} \sum_{i=1}^{m}\left(\xi_{i}-\sum_{j=1}^{k} x_{i j} \beta\right)^{2}\right) \times f\left(p_{i}, \boldsymbol{\beta}, \tau_{v}\right) .
\end{aligned}
$$

Karena distribusi posterior gabungan menghasilkan nilai yang kompleks, maka digunakan teknik MCMC algoritma Gibbs sampling untuk mencari nilai penduga.

Pendugaan tidak langsung dengan menggunakan metode Small Area Estimation Hierarchical Bayes menghasilkan pendugaan persentase kasus kusta basah di tingkat kabupaten/kota yang cenderung lebih baik daripada pendugaan langsung dapat dilihat pada rata-rata standar error yang dihasilkan oleh metode Small Area Estimation Hierarchical Bayes memiliki nilai yang lebih kecil yaitu 0,0048 daripada standar error pada pendugaan langsung.

\section{Ucapan Terima kasih}

Penulis mengucapkan terimakasih kepada Ibu Izzati Rahmi H.G., M.Si, Ibu Dr. Ferra Yanuar dan Ibu Dr. Des Welyyanti yang telah memberikan masukan dan saran sehingga paper ini dapat diselesaikan dengan baik.

\section{Daftar Pustaka}

[1] Bain, L.J., dan M. Engelhardt. 1992. Introduction to Probability and Mathematical Statistic, Second Edition. Duxbuy Press: California.

[2] Dinkes Provinsi Jatim. 2018. Profil Dinas Keshatan Provinsi Jawa Timur Tahun 2018. Dinkes Provinsi Jatim.

[3] Ghosh, M, dan J.K.N. Rao. 1994. Small Area Estimation: An Appraisal. Statistical Science. Vol 9: 55 - 93.

[4] Ntzoufras, I. 2009. Bayesian Modeling Using Winbugs. John Wiley and Sons, New Jersey.

[5] Rao, J.N.K. 2003. Small Area Estimation. John Wiley and Sons, New Jersey. 